\title{
Effect of sepsis on the action potential and cardiac serotonin response in rats
}

\author{
ZHENG-JIANG LIU ${ }^{1}$, HUA LIU ${ }^{1}$, CHANGDONG WU ${ }^{2}$ and KEDONG XUE ${ }^{2}$ \\ ${ }^{1}$ Department of Cardiology, Qingyuan People's Hospital, The Sixth Affiliated Hospital of Guangzhou Medical University, \\ Qingyuan, Guangdong 511500; ${ }^{2}$ Intensive Medicine Unit, The People's Hospital of Xinjiang Uygur Autonomous Region, \\ Urumqi, Xinjiang Uygur Autonomous Region 830001, P.R. China
}

Received March 20, 2018; Accepted May 16, 2019

DOI: $10.3892 / \mathrm{etm} .2019 .7810$

\begin{abstract}
The current study aimed to investigate the effect of sepsis on rat serotonin (5-HT) responses and cardiac action potentials. A total of 20 rats were randomly divided into a sepsis and control group (each, $n=10$ ). Rat hearts were harvested and perfused using the Langendorff method 18-h after the induction of sepsis, which was assessed using cecal puncture. Cardiac action potential was subsequently measured using a multichannel electrophysiology instrument. Immunohistochemistry and quantitative analysis were performed to identify the effect of sepsis on myocardial 5-HT expression. The results revealed that mitochondrial changes were present in septic rat hearts. Heart rate $(361.10 \pm 12.29$ bpm vs. $348.60 \pm 12.38$ bpm; $\mathrm{P}<0.05)$ was significantly higher, atrial action potential duration $(106.40 \pm 2.95 \mathrm{~ms}$ vs. $86.60 \pm 4.12 \mathrm{~ms} ; \mathrm{P}<0.01)$ was significantly longer and the area $\left(0.62 \pm 0.06 \mu \mathrm{m}^{2}\right.$ vs. $\left.0.39 \pm 0.05 \mu \mathrm{m}^{2} ; \mathrm{P}<0.05\right)$ and number $(0.92 \pm 0.02 /$ field vs. $0.46 \pm 0.01 /$ field; $\mathrm{P}<0.01)$ of myocardial cells were significantly higher in the septic compared with the control group. These results demonstrated that 5 -HT prolongs the atrial action potential, increases heart rate and aggravates myocardial injury, indicating that it may therefore be one of the factors that leads to cardiac dysfunction in sepsis.
\end{abstract}

\section{Introduction}

Sepsis is a systemic inflammatory syndrome, which results from infection. Due to septic shock and its deleterious effects on cardiac function, sepsis is the leading cause of death in critically ill patients (1). Cardiac dysfunction aggravates septic syndrome, influences its prognosis and is very common in patients with sepsis (2). A significantly higher mortality rate is observed in patients with sepsis and cardiac dysfunction (70-90\%)

Correspondence to: Dr Zheng-Jiang Liu, Department of Cardiology, Qingyuan People's Hospital, The Sixth Affiliated Hospital of Guangzhou Medical University, 22 Shuguang Second Road, Qingcheng, Qingyuan, Guangdong 511500, P.R. China

E-mail:29542006j@sina.com

Key words: sepsis, serotonin, action potential compared with patients exhibiting sepsis alone, implying that sepsis-associated mortality may be associated with cardiac dysfunction. Pro-inflammatory factors, mitochondrial structural dysfunction, dysfunction of the autonomic nervous system, myocardial cell injury and apoptosis have all been associated with the pathogenesis of sepsis (3-5). In particular, pro-inflammatory factors including cytokines, may serve a critical role in the pathogenesis of sepsis (5). Due to the fact that heart failure associated mortality in patients with sepsis is high, the presence of heart failure may be used as a predictor of survival.

Serotonin (5-HT) neurons regulate the function of the visceral sensory system, motor nervous system and autonomic nervous system and are widely distributed in these areas (6). 5-HT and its receptors are widely distributed in the cardiovascular system and serve an important role in the regulation of cardiovascular function (1). The abnormal regulation of 5-HT can result in the development of cardiovascular disease $(7,8)$. This is due to the involvement of 5-HT in cardiac remodeling, a process that includes myocardial cell hypertrophy, apoptosis and necrosis, which can lead to heart failure (9). High 5-HT concentrations are associated with an increased severity of heart failure symptoms and systolic dysfunction (10).

Mitochondria are an important site for cellular oxidation and provide $\sim 95 \%$ of the energy a cell requires (11). Mitochondrial dysfunction in the myocardium is a major cause of myocardial impairment in sepsis (11). A previous study demonstrated that stress may result in myocardial injury (12) with another study identifying that stress leads to the impairment of myocardial ultrastructure, particularly in mitochondria, resulting in the apoptosis of myocardial cells (13). Mitochondria are important for the maintenance of normal function in myocardial cells $(14,15)$. In the current study, the effects of sepsis on 5-HT responses and cardiac action potentials were investigated using a rat model.

\section{Materials and methods}

Animals. A total of 20 healthy adult male Sprague-Dawley rats (weight, 180-250 g; age, 2-3 months) were provided by the Experimental Animal Center of Southern Medical University (qualified certificate number: 44002100014706). Rats were housed in a specific pathogen-free facility at $21 \pm 2^{\circ} \mathrm{C}$ and a humidity of $50 \pm 10 \%$, under a 12 -h light/dark cycle (lights on 
07:00-19:00), with free access to food and drinking water. After a 1-week adaption period in the Animal Feeding Center of Qingyuan People's Hospital, The Sixth Affiliated Hospital of Guangzhou Medical University, rats were randomly divided into a sepsis and a control group (each, $\mathrm{n}=10$ ). The experiments of the current study conformed to the Guide for the Care and Use of Laboratory Animals, published by the National Institutes of Health (publication no. 85-23) and were approved by the Animal Ethics Committee of the People's Hospital of Xinjiang (Xinjiang, China). All efforts were made to minimize the suffering and number of rats used in the current study.

Induction of sepsis. After anesthesia the sterile intraperitoneal administration of $10 \%$ chloral hydrate $(300 \mathrm{mg} / \mathrm{kg})$, a $3 \mathrm{~cm}$ median abdominal incision was made. The cecum was ligated with a 4-0 silk suture $5 \mathrm{~cm}$ away from the tip. Two cecal perforations were performed using a 14-gauge needle at the free cecal end, following which the cecum was replaced and the abdominal incision closed. Penicillin (100,000-150,000 U/250 g) was intraperitoneally administered prior to and following surgery. Normal saline $(5 \mathrm{ml} / 100 \mathrm{~g})$ was subcutaneously administered to replace body fluid lost during surgery. There were no signs of peritonitis following anesthesia. In the normal group, a sham procedure without cecal ligation was performed $(16,17)$. The rats were monitored every $6-\mathrm{h}$ for 18 -h of continuous behavior observation.

Action potential duration in ex vivo atria and ventricles. At $18 \mathrm{~h}$ post surgery, all rats were deeply anesthetized with an intraperitoneal injection of $10 \%$ chloral hydrate $(300 \mathrm{mg} / \mathrm{kg})$ and subsequently sacrificed by cervical dislocation. Rat hearts were extracted rapidly after opening the chest and perfused using the Langendorff method (18) with Krebs-Henseleit buffer ( $\mathrm{NaCl}, 118.5 \mathrm{mM} ; \mathrm{KCl}, 4.7 \mathrm{mM} ; \mathrm{CaCl}_{2}, 2.5 \mathrm{mM} ; \mathrm{NaHCO}_{3}$, $25 \mathrm{mM}$; $\mathrm{MgSO}_{4}, 1.2 \mathrm{mM}$; $\mathrm{KH}_{2} \mathrm{PO}_{4}, 1.2 \mathrm{mM}$; glucose, $11 \mathrm{~g}$; $\mathrm{pH}=7.4$ ) at a temperature of $36^{\circ} \mathrm{C}$, with $95 \% \mathrm{O}_{2}$ and $5 \% \mathrm{CO}_{2}$ (flow rate, $1.5 \mathrm{ml} / \mathrm{min}$ ). Atrial and ventricular action potential duration was measured $30 \mathrm{~min}$ after perfusion using a multichannel electrophysiology instrument (Lead-2000; Sichuan Jinjiang Electronic Science and Technology Co., Ltd.).

Sample collection. Two pieces of left ventricular apical tissue were fixed at room temperature overnight in $10 \%$ formaldehyde solution, embedded in paraffin, cut into $4 \mu \mathrm{m}$ sections and stained with hematoxylin and eosin at $37^{\circ} \mathrm{C}$ for 24 -h or subjected to 5-HT immunohistochemistry. The remaining apical tissue was sectioned, fixed with $2.5 \%$ glutaraldehyde at $37^{\circ} \mathrm{C}$ for $8 \mathrm{~h}$, dehydrated with an acetone series (a gradient dehydration of $85 \%$ alcohol-95\% alcohol-anhydrous alcohol), embedded with neutral resin, stained with uranyl acetate and lead citrate at $37^{\circ} \mathrm{C}$ for $8 \mathrm{~h}$ and cut into ultrathin sections ( $0.5 \mathrm{~mm}$ thick). The ultrastructure of the myocardial cells was then evaluated using transmission electron microscopy.

Immunohistochemistry. Paraffin-embedded sections were dewaxed, treated with $3 \% \mathrm{H}_{2} \mathrm{O}_{2}$ at room temperature for $10 \mathrm{~min}$ to remove endogenous peroxidase activity then washed with $\mathrm{PBS}$ three times. Samples were then microwave irradiated at $92-98^{\circ} \mathrm{C}$ for antigen retrieval and dehydrated with an acetone series (a gradient dehydration of $85 \%$ alcohol-95\% alcohol-anhydrous alcohol). Samples were then incubated with rabbit primary antibody against serotonin (1:100; cat. no. PB0442; Wuhan Boster Biological Technology, Ltd.) overnight at $4^{\circ} \mathrm{C}$. Samples were incubated with goat anti-rabbit horseradish peroxidase-conjugated goat anti-rabbit secondary antibody $(1: 1,000$; cat. no. SV-002; Wuhan Boster Biological Technology, Ltd.) at $37^{\circ} \mathrm{C}$ for $30 \mathrm{~min}$ then washed with PBS three times. Samples were stained with 3,3'-diaminobenzidine (cat. no. AR1022; Boster Biological Technology, Ltd.) at $37^{\circ} \mathrm{C}$ for $30 \mathrm{~min}$. Distilled water was used to dilute the kit reagents (cat. no. AR1022; Wuhan Boster Biological Technology, Ltd.), tissue sections were treated with a mixture of kit reagents $\mathrm{A}, \mathrm{B}$ and $\mathrm{C}$, developed at room temperature then exposed to running water to terminate the reaction. Finally, sections were counterstained with hematoxylin at $37^{\circ} \mathrm{C}$ for $30 \mathrm{~min}$, cleared with ethanol and hydrochloric acid then mounted in resin. Three sections from each tissue were observed using an Olympus optical microscope (Olympus Corporation). Five fields (magnification, x200) were randomly selected in each section using the Kontron IBAS computerized image analysis system (Carl Zeiss AG). The positive reaction area/total area and positively stained cells/total number of cells in the same area was measured.

Statistical analysis. Data are expressed as the mean \pm standard deviation and were analyzed using SPSS 16.0 software (SPSS, Inc.). A Student's t-test was used for comparison between the two groups and $\mathrm{P}<0.05$ was considered to indicate a statistically significant result.

\section{Results}

Rat behavior and pathologic changes in myocardial cells. In the sepsis group, 6-8 h after surgery, rats exhibited bradykinesia, tachypnea, a hunched posture and reacted slowly to stimuli. At $18 \mathrm{~h}$ after surgery, conjunctival hyperemia, watery stool, intermittent trembling and coughing was observed. In contrast, the rats in the control group exhibited no adverse effects subsequent to surgery. In the sepsis group, the dissected heart was a dark color, soft and friable, whereas the control group heart was bright red and hard. There were no differences in the mass of the whole heart or the mass of ventricles between the control group $(0.00267 \pm 0.000205)$ and the sepsis group $(0.00273 \pm 0.000192)$. Following hematoxylin and eosin staining, interstitial congestion, edema and inflammatory cell infiltration were observed in the myocardial tissue of septic rats, but not in necrotic myocardial cells (Fig. 1A and B). Transmission electron microscopy revealed disordered myocardial myofibers and mitochondria, mitochondrial enlargement, swelling and vacuolar degeneration of the mitochondrial cristae. Myocardial fibers were arranged irregularly, some were distended, muscle bundles were separated, $Z$ lines and intercalated disks were distorted. The distance between $\mathrm{Z}$ lines was also shortened and the nuclear membranes were irregular. Furthermore, the mitochondrial membranes were fragmented, mitochondrial cristae were absent and mitochondria were disordered and vacuolated (Fig. 2B). However, normal histology and ultrastructure was present in the hearts of the control group (Fig. 2A).

Heartrate andduration of actionpotentials. At 18-h post-surgery, the atrium action potentials in cardiac tissue were significantly 


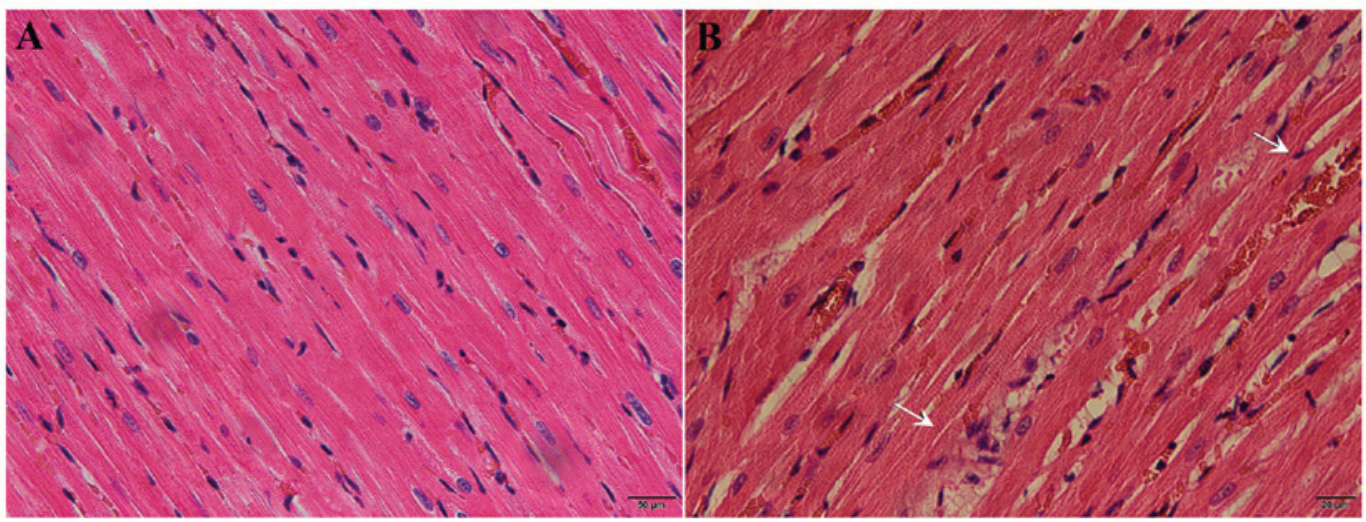

Figure 1. Immunohistochemistry results of control and septic rat hearts. Hematoxylin and eosin staining of (A) control and (B) septic heart tissue (magnification, x200). The arrows indicated inflammatory changes in myocardial tissue of septic rats.
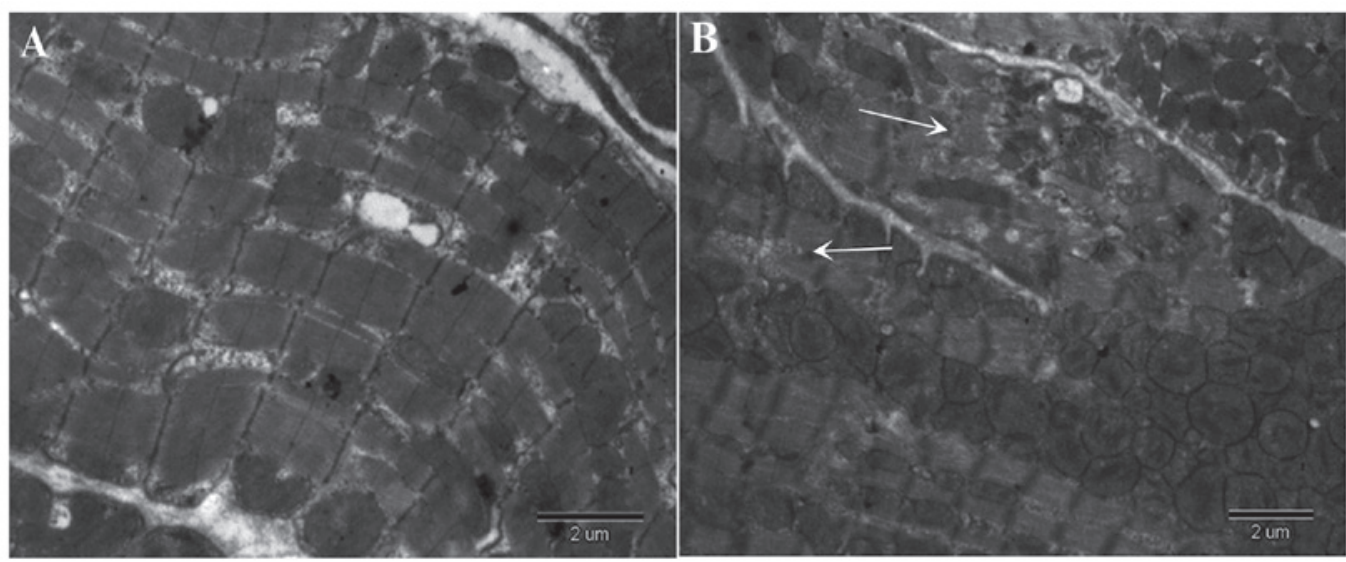

Figure 2. Transmission electron microscopy of control and septic rat hearts. Representative images of (A) control and (B) septic rat hearts (magnification, $\mathrm{x} 10,000)$. The arrows indicated destruction of myocardial cell structure.

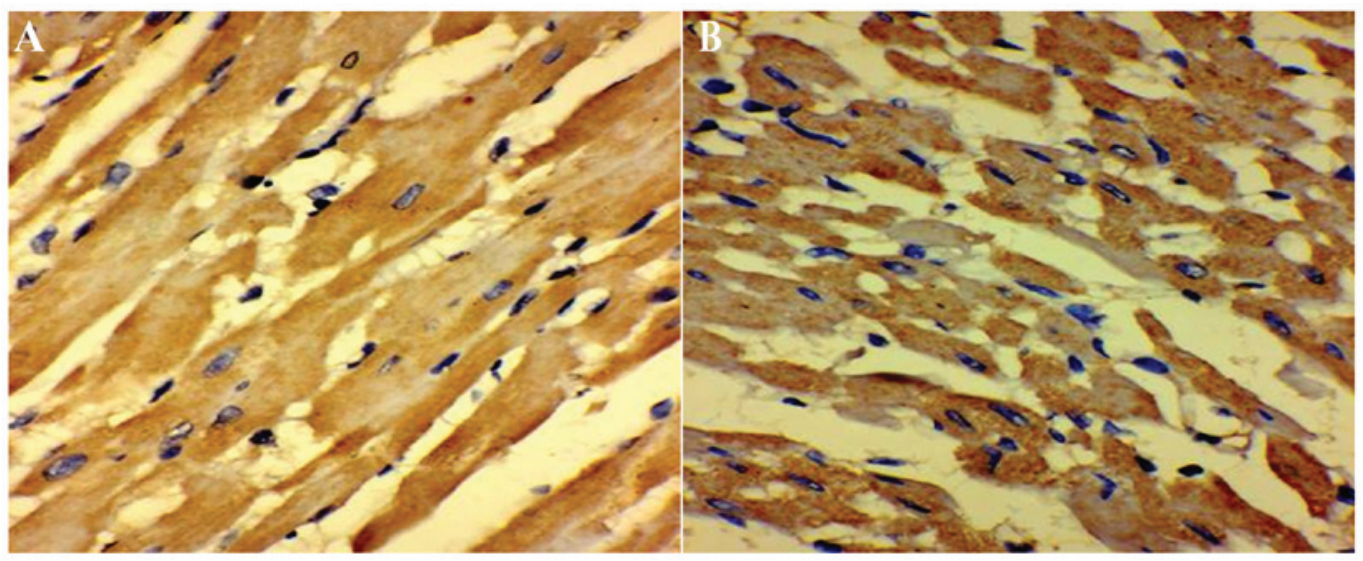

Figure 3. Serotonin immunohistochemistry of cardiac tissue in control and septic rats. Representative images of 5-HT stains in (A) control and (B) septic rat myocardial tissue (optical microscope; magnification, x400). 5-HT, serotonin.

longer $(\mathrm{P}<0.01)$ and heart rate was significantly higher $(\mathrm{P}<0.05)$ in the sepsis group compared with the control group. There was no significant difference in ventricular action potential between the sepsis and control groups $(\mathrm{P}>0.05$; Table I).

Immunohistochemistry of cardiac tissue. As presented in Table II, 5-HT-positive nerve fibers were observed in the septic and control groups. In the control group, myocardial fibers were arranged in an orderly manner with less interstitial matrix, and with 5-HT-positive nerve fibers projecting along the muscle bundles. However, in the sepsis group, myocardial fibers were more diffuse with more interstitial matrix. The area of 5-HT-positive myocardial cells and staining intensity was also significantly higher $(\mathrm{P}<0.01$; Fig. $3 \mathrm{~A}$ and $\mathrm{B}$; Table II). 
Table I. Rat heart rate, atrial/ventricular action potentials and heart/body mass following cecal ligation and puncture/sham surgery.

\begin{tabular}{lccccc}
\hline Group & Number & Heart rate $(\mathrm{bpm})$ & Atrium $(\mathrm{ms})$ & Ventricles (ms) & Heart/body mass \\
\hline Sepsis & 10 & $361.10 \pm 12.39^{\mathrm{a}}$ & $106.40 \pm 2.95^{\mathrm{b}}$ & $155.80 \pm 3.15$ & $0.00273 \pm 0.000192$ \\
Control & 10 & $348.60 \pm 12.38$ & $86.60 \pm 4.12$ & $153.10 \pm 3.84$ & $0.00267 \pm 0.000205$ \\
t-value & & -2.15 & -12.364 & -1.717 & 1.116 \\
P-value & $<0.045$ & $<0.001$ & 0.1104 & 0.293 \\
\hline
\end{tabular}

${ }^{\mathrm{a}} \mathrm{P}<0.05 ;{ }^{\text {b }}<0.01$ vs. control group.

Table II. Serotonin protein expression in the left ventricular apex following cecal ligation and puncture/sham surgery.

\begin{tabular}{lccc}
\hline Group & Number of rats & Area of positive staining $\left(\mu \mathrm{m}^{2}\right)$ & Number of positive cells $($ cells/field) \\
\hline Control & 10 & $0.39 \pm 0.05$ & $0.46 \pm 0.01$ \\
Sepsis & 10 & $0.62 \pm 0.06^{\mathrm{a}}$ & $0.92 \pm 0.02^{\mathrm{b}}$ \\
t-value & & 0.477 & 0.589 \\
P-value & $<0.05$ & $<0.001$ \\
\hline
\end{tabular}

${ }^{\mathrm{a}} \mathrm{P}<0.05 ;{ }^{\mathrm{b}} \mathrm{P}<0.01$ vs. control group.

\section{Discussion}

Sepsis results in heart failure in $\sim 50 \%$ of patients, accounting for the higher mortality rate in patients with heart failure compared with those who have sepsis alone (1). Patients with sepsis-induced cardiac injury often demonstrate changes in electrocardiograms. Makara et al (19) demonstrated that within 48 h of Francisella novicida infection, R waves became more prominent, QRS intervals were prolonged and heart rate was higher in a rat sepsis model. In the aforementioned study, the changes in electrocardiogram became more pronounced at $96 \mathrm{~h}$, indicating severe electrical conduction defects. The results of the rat model used in the current study demonstrated a higher heart rate and longer atrial action potentials, which are indicative of altered ion channel function, an atrial electrophysiologic disorder and/or altered atrial structure (20). Atrial disease has a marked effect on cardiac function and is associated with a high risk of arrhythmia and stroke $(21,22)$. The results of the current study indicated that cardiac injury begins at the time of bacterial infection, with atrial cells responding quickly and significantly to a pathologic stimulus. This is consistent with the hypothesis that electrophysiological changes in the heart caused by bacterial sepsis increase mortality (23).

Inflammatory mediators and myocarditis are considered to be contributors to the high incidence of sudden death, severe arrhythmia and heart failure associated with sepsis (24). 5-HT is an auto-active substance that is not only associated with inflammation and the immune response, but also serves roles in a number of other pathophysiologic processes. Humoral immunity and/or cellular responses occur in response to tissue damage, inducing 5-HT release, which binds to its specific cell receptors and results in an inflammatory response (25). When the physiologic state of the body changes, 5-HT directly or indirectly alters the physiology or structure of target organs (7). However, 5-HT also increases calcium conductance, triggering spontaneous pulsatile activity in resting cells (26). In sepsis, a high concentration of 5-HT increases myocardial free $\mathrm{Ca}^{2+}$ concentration, which leads to calcium overload in myocardial cells. Sepsis also activates the 5-HT4 receptor and enhances $\mathrm{Ca}^{2+}$ influx via the cAMP-dependent pathway, triggering cardiac L-type $\mathrm{Ca}^{2+}$ channels and leading to diastolic depolarization (27). This results in atrial action potentials being prolonged, atrial electrophysiologic disorder and subsequently, contractile dysfunction (28).

Mitochondria are important in the maintenance of cardiac function. Accumulating evidence has indicated that mitochondria contribute to the pathophysiology of cardiac dysfunction associated with infection (29). 5-HT-induced myocardial $\mathrm{Ca}^{2+}$ overload is likely the result of inflammatory cytokines, including tumor necrosis factor- $\alpha$, interleukin (IL)-1 and IL-6, inducing apoptotic signaling in myocardial mitochondria (25). Most cardiovascular diseases, such as hypertension, atherosclerosis, coronary artery disease, and myocardial infarction are associated with the opening of mitochondrial membrane pores (30). This is followed by a series of events including the loss of mitochondrial transmembrane potential, the uncoupling of the respiratory chain, leakage of mitochondrial $\mathrm{Ca}^{2+}$, excessive production of reactive oxygen species (15) and the release of resident mitochondrial proteins, which include apoptosis-inducing factor cytochrome $\mathrm{c}$ and second mitochondrial-derived activator caspase (31). These events lead to mitochondrial dysfunction, which involves the reduction of ATP production, an increase in oxidation products, imbalances in the regulation of mitochondrial proteins and ultimately cell apoptosis, all of which are associated with inadequate energy supply to the heart (11). The results of the aforementioned studies are consistent with the contention that 
abnormal mitochondrial energy metabolism is the underlying mechanism of sepsis-associated cardiac mortality.

5-HT activates the cell apoptosis pathway and induces the production of toxic oxygen free radicals, which aggravate cardiac dysfunction (32). Continuous inflammation and cardiac exposure to cytokines may lead to left ventricular dysfunction, which results in poor muscle strength and altered myocardial metabolism (5). This contributes to myocardial remodeling and therefore promotes the progression of heart failure (32). Oxidative stress is also a cause of cardiac injury. All these factors change the polarization and contractility of myocardial cells, resulting in cardiac dysfunction (15). The pathologic changes identified in the present study, which include larger myocardial mitochondria, swollen cristae and vacuolar degeneration, are consistent with oxidative stress. An insufficient energy supply to the heart may delay the recovery of myocardial function, lead to cardiac electrical disorders, activate the sympathetic nervous system, induce 4-phase depolarization, increase heart rate and eventually result in heart failure, shock and death (33).

The heart is a vulnerable target organ in sepsis $(1,4)$. Cardiac dysfunction is very common in sepsis/septic shock and is associated with a high mortality rate. However, the molecular mechanisms underlying the pathophysiologic changes in myocardial cells are yet to be elucidated (34). 5-HT is a widely distributed, endogenous monoamine that serves as a pro-inflammatory factor. However, its role in cardiovascular regulation depends on the distribution of its receptor (35). In the current study, a preliminarily investigation of the pathophysiologic role of 5-HT in the septic heart was undertaken. During sepsis, the regulation of 5-HT is abnormal, but whether 5-HT receptor antagonists reverse the pathologic effects of sepsis-induced endogenous 5-HT elevation and the dose-response associations of 5-HT receptor antagonists in the heart, was not assessed in the present study and therefore warrants further investigation. Furthermore, the most appropriate parameters for the assessment of cardiac dysfunction during sepsis, including markers of oxidative stress, cytochrome $\mathrm{c}$ activity, mitochondrial ATP, oxidation products and mitochondrial $\mathrm{Ca}^{2+}$, should be investigated in future studies.

\section{Acknowledgements}

Not applicable.

\section{Funding}

This work was supported by Hospital Fund of Qingyuan People's Hospital, The Sixth Affiliated Hospital of Guangzhou Medical University (grant no. 2017-1014106).

\section{Availability of data and materials}

The datasets used and/or analyzed during the current study are available from the corresponding author on reasonable request.

\section{Authors' contribution}

ZJL, HL, CDW and KDX performed the experiments. HL and KDX collected and analyzed the data. ZJL and CDW conceived and designed the study. ZJL wrote the manuscript. All authors read and approved the manuscript.

\section{Ethics approval and consent to participate}

This study was approved by the Animal Research Ethics Committee of The Sixth Affiliated Hospital of Guangzhou Medical University. All procedures performed in studies involving animals were in accordance with the ethical standards of the institution or practice at which the studies were conducted.

\section{Patient consent for publication}

Not applicable.

\section{Competing interests}

The authors declare that they have no competing interests.

\section{References}

1. Zaky A,Deem S, Bendjelid K and Treggiari MM: Characterization of cardiac dysfunction in sepsis: An ongoing challenge. Shock 41: 12-24, 2014.

2. Annane D, Bellissant E and Cavaillon JM: Septic shock. Lancet 365: 63-78, 2005.

3. Angus DC, Linde-Zwirble WT, Lidicker J, Clermont G, Carcillo J and Pinsky MR: Epidemiology of severe sepsis in the United States: Analysis of incidence, outcome, and associated costs of care. Crit Care Med 29: 1303-1310, 2001.

4. Merx MW and Weber C: Sepsis and the heart. Circulation 116: 793-802, 2007.

5. Alvarez S, Vico T and Vanasco V: Cardiac dysfunction, mitochondrial architecture, energy production, and inflammatory pathways: Interrelated aspects in endotoxemia and sepsis. Int J Biochem Cell Biol 81: 307-314, 2016

6. Vikenes K, Farstad M and Nordrehaug JE: Serotonin is associated with coronary artery disease and cardiac events. Circulation 100: 483-489, 1999.

7. Liu MY, Ren YP, Zhang LJ and Ding JY: Pretreatment with Ginseng Fruit Saponins affects serotonin expression in an experimental comorbidity model of myocardial infarction and depression. Aging Dis 7: 680-686, 2016.

8. Cowen P: Serotonin depression and antidepressant action. S Afr J Psychiatr 19: 94, 2013.

9. Selim AM, Sarswat N, Kelesidis I, Iqbal M, Chandra R and Zolty R: Plasma aerotonin in heart failure: Possible marker and potential treatment target. Heart Lung Circ 26: 442-449, 2017.

10. Villeneuve C, Guilbeau-Frugier C, Sicard P, Lairez O, Ordener C, Duparc T, De Paulis D, Couderc B, Spreux-Varoquaux O, Tortosa F, et al: p53-PGC-1 $\alpha$ pathway mediates oxidative mitochondrial damage and cardiomyocyte necrosis induced by monoamine oxidase-A upregulation: Role in chronic left ventricular dysfunction in mice. Antioxid Redox Signal 18: 5-18, 2013.

11. Rudiger A and Singer M: Mechanisms of sepsis-induced cardiac dysfunction. Crit Care Med 35: 1599-1608, 2007.

12. Liu AL, Zhu HD, Yu XZ, Liu J, Ma S, Liu ZY and Guo SB: The mechanisms of LPS-induced cardiac dysfunction in septic mice. Chin J Emerg Med 24: 825-829, 2015.

13. Walley KR: Deeper understanding of mechanisms contributing to sepsis-induced myocardial dysfunction. Crit Care 18: $137,2014$.

14. Kong HL, Li ZQ, Zhao YJ, Zhao SM, Zhu L, Li T, Fu Y and Li HJ: Ginsenoside Rb1 protects cardiomyocytes against $\mathrm{CoCl} 2$-induced apoptosis in neonatal rats by inhibiting mitochondria permeability transition pore opening. Acta Pharmacol Sin 31: 687-695, 2010.

15. Passarelli C, Tozzi G, Pastore A, Bertini E and Piemonte F: GSSG-mediated complex I defect in isolated cardiac mitochondria. Int J Mol Med 26: 95-99, 2010. 
16. Williams DL, Ha T, Li C, Kalbfleisch JH, Schweitzer J, Vogt W and Browder IW: Modulation of tissue Toll-like receptor 2 and 4 during the early phases of polymicrobial sepsis correlates with mortality. Crit Care Med 31: 1808-1818, 2003.

17. Ha T, Hua F, Grant D, Xia Y, Ma J, Gao X, Kelley J, Williams DL, Kalbfleisch J, Browder IW, et al: Glucan phosphate attenuates cardiac dysfunction and inhibits cardiac MIF expression and apoptosis in septic mice. Am J Physiol Heart Circ Physiol 291: H1910-H1918, 2006.

18. Liu Z, Liu H and Zeng ZH: Chronic unpredictable mild stress causing cardiac and thoracic spinal cord electrophysiological abnormalities may be associated with increased cardiac expression of serotonin and growth-associated protein-43 in rats. Biomed Res Int 2018: 8697913, 2018.

19. Makara MA, Hoang KV, Ganesan LP, Crouser ED, Gunn JS Turner J, Schlesinger LS, Mohler PJ and Rajaram MV: Cardiac electrical and structural changes during bacterial infection: An instructive model to study cardiac dysfunction in sepsis. J Am Heart Assoc 5: pii: e003820, 2016.

20. Christ T, Rozmaritsa N, Engel A, Berk E, Knaut M, Metzner K, Canteras M, Ravens U and Kaumann A: Arrhythmias, elicited by catecholamines and serotonin, vanish in human chronic atrial fibrillation. Proc Natl Acad Sci USA 111: 11193-11198, 2014.

21. Goette A, Kalman JM, Aguinaga L, Akar J, Cabrera JA, Chen SA, Chugh SS, Corradi D, D'Avila A, Dobrev D, et al: EHRA/HRS/APHRS/SOLAECE expert consensus on Atrial cardiomyopathies: Definition, characterisation, and clinical implication. J Arrhythm 32: 247-278, 2016.

22. Goette A, Bukowska A, Dobrev D, Pfeiffenberger J, Morawietz $H$, Strugala D, Wiswedel I, Röhl FW, Wolke C, Bergmann S, et al: Acute atrial tachyarrhythmia induces angiotensin II type 1 receptor-mediated oxidative stress and microvascular flow abnormalities in the ventricles. Eur Heart J 30: 1411-1420, 2009.

23. Tucker NR and Ellinor PT: Emerging directions in the genetics of atrial fibrillation. Circ Res 114: 1469-1482, 2014.

24. Grün S, Schumm J, Greulich S, Wagner A, Schneider S, Bruder O, Kispert EM, Hill S, Ong P, Klingel K, et al: Long-term follow-up of biopsy-proven viral myocarditis: Predictors of mortality and incomplete recovery. J Am Coll Cardiol 59: 1604-1615, 2012.

25. Liu Z, Zeng Z, Wu C and Liu H: Tropisetron inhibits sepsis by repressing hyper-inflammation and regulating the cardiac action potential in rat models. Biomed Pharmacother 110: 380-388, 2019.
26. Pennec JP, Talarmin H, Droguet M, Giroux-Metgès MA, Gioux $\mathrm{M}$ and Dorange $\mathrm{G}$ : Characterization of the voltage-activated currents in cultured atrial myocytes isolated from the heart of the common oyster Crassostrea gigas. J Exp Biol 207: 3935-3944, 2004.

27. Rahme MM, Cotter B, Leistad E, Wadhwa MK, Mohabir R, Ford AP, Eglen RM and Feld GK: Electrophysiological and antiarrhythmic effects of the atrial selective 5-HT(4) receptor antagonist RS-100302 in experimental atrial flutter and fibrillation. Circulation 100: 2010-2017, 1999.

28. Galindo-Tovar A, Vargas ML, Escudero E and Kaumann AJ: Ontogenic changes of the control by phosphodiesterase- 3 and -4 of 5-HT responses in porcine heart and relevance to human atrial 5-HT(4) receptors. Br J Pharmacol 156: 237-249, 2009.

29. Singer M: Mitochondrial function in sepsis: Acute phase versus multiple organ failure. Crit Care Med 35 (9 Suppl): S441-S448, 2007.

30. Wang X, Liu X, Kong R, Zhan R, Wang X, Leng X, Gong J, Duan M, Wang L, Wu L and Qian L: NGFI-B targets mitochondria and induces cardiomyocyte apoptosis in restraint-stressed rats by mediating energy metabolism disorder. Cell Stress Chaperones 14: 639-648, 2009.

31. Xinxing W, Hong F, Rui Z, Yun Z, Jingbo G and Lingiia Q: Phosphorylated nerve growth factor-induced clone B (NGFI-B) translocates from the nucleus to mitochondria of stressed rat cardiomyocytes and induces apoptosis. Stress 15: 545-553, 2012.

32. Briasoulis A, Androulakis E, Christophides T and Tousoulis D: The role of inflammation and cell death in the pathogenesis, progression and treatment of heart failure. Heart Fail Rev 21: 169-176, 2016.

33. Liu ZJ, Liu H, Xue KD and Wu S: Experimental research of heart serotonin and myocardial action potential change in the model of sepsis rats. Chin J Clinicians 10: 72-75, 2016.

34. Chung HY, Kollmey AS, Schrepper A, Kohl M, Bläss MF, Stehr SN, Lupp A, Gräler MH and Claus RA: Adjustment of dysregulated ceramide metabolism in a murine model of sepsis-induced cardiac dysfunction. Int J Mol Sci 18: pii: E839, 2017.

35. Mössner R and Lesch KP: Role of serotonin in the immune system and in neuroimmune interactions. Brain Behav Immun 12: 249-271, 1998. 